\title{
Expiratory Pause Maneuver to Assess Inspiratory Muscle Pressure During Assisted Mechanical Ventilation: A Bench Study
}

\author{
Richard H Kallet, Justin S Phillips, Travis J Summers, Gregory Burns, Lance Pangilinan, \\ Logan Carothers, Earl R Mangalindan, and Michael S Lipnick
}

\begin{abstract}
BACKGROUND: The generation of excessive inspiratory muscle pressure $\left(\mathbf{P}_{\text {mus }}\right)$ during assisted mechanical ventilation in patients with respiratory failure may result in acute respiratory muscle injury and/or fatigue, and exacerbate ventilator-induced lung injury. A readily available noninvasive surrogate measure of $\mathbf{P}_{\text {mus }}$ may help in titrating both mechanical ventilation and sedation to minimize these risks. This bench study explored the feasibility and accuracy of using a ventilator's expiratory pause hold function to measure $P_{\text {mus }}$ across multiple operators. METHODS: A standardized technique for executing a brief ( $<1 \mathrm{~s})$ expiratory pause maneuver was used to measure the airway occlusion pressure change $\left(\Delta P_{\text {aw }}\right)$ by using 3 simulated $P_{\text {mus }}\left(\Delta P_{\text {mus }}: 5,10,15 \mathrm{~cm} \mathrm{H}_{2} \mathrm{O}\right)$ under (1) pressure support ventilation $(0$, $10,15 \mathrm{~cm} \mathrm{H}_{2} \mathrm{O}$ ), (2) volume and pressure-regulated volume ventilation, (3) flow and pressure-triggering, and (4) varying levels of PEEP and pressure-rise time. Individual and grouped measurements were made by 4-7 clinicians on 3 different ventilators. The concordance between occlusion $\Delta P_{a w}$ and $\Delta$ $P_{\text {mus }}$ was arbitrarily set at $\leq 2 \mathrm{~cm} \mathrm{H}_{2} \mathrm{O}$. Data were evaluated by using analysis of variance and the Tukey-Kramer posttest. Correlation was assessed by using the Pearson R test; bias and precision were assessed by using the Bland-Altman method. Alpha was set at 0.05. RESULTS: Grouped expiratory pause maneuver measurements of occlusion $\Delta P_{\text {aw }}$ across simulated $\Delta P_{\text {mus, }}$, mode and level of ventilatory support showed reasonable concordance, regardless of the ventilator used. Occlusion $\Delta \mathbf{P}_{\text {aw }}$ accuracy frequently decreased by $\sim 3 \mathrm{~cm} \mathrm{H}_{2} \mathrm{O}$ when both pressure support ventilation and $\Delta \mathrm{P}_{\text {mus }}$ reached $15 \mathrm{~cm} \mathrm{H}_{2} \mathrm{O}$. Expiratory pause maneuver accuracy was not affected by trigger mechanism and/or sensitivity, PEEP, or the post-trigger pressurization rate. In general, only small differences in $\Delta P_{a w}$ occurred among the individual operators. CONCLUSIONS: The expiratory pause maneuver generally provided reproducible, stable approximations of $\Delta P_{\text {mus }}$ across ventilators and ventilator settings, and a range of simulated effort. Technique standardization produced relatively consistent results across multiple operators. The expiratory pause maneuver seemed feasible for general use in monitoring inspiratory effort during assisted mechanical ventilation. Key words: expiratory pause maneuver; assisted mechanical ventilation; inspiratory effort. [Respir Care 2021;66(11):1649-1656. (C) 2021 Daedalus Enterprises]
\end{abstract}

\section{Introduction}

A major goal of mechanical ventilation is to control patient work of breathing. During critical illness, abnormal chest mechanics in concert with high resting minute ventilation demand place excessive workloads on the ventilatory muscles, which lead to fatigue, acute injury, and the potential for overt muscle failure. ${ }^{1,2}$ Although the ventilator is adjusted with the objective of either normalizing or minimizing patient work of breathing, the severity of illness often renders these adjustments alone insufficient. Consequently, deep sedation and sometimes neuromuscular blockade are required to gain adequate control over both the power of breathing and gas exchange. Severe respiratory failure thus presents a management conundrum because most patients are at risk for developing acute ventilatory muscle injury caused by 1 of 2 opposing mechanisms: disuse atrophy from prolonged periods of either passive or oversupported ventilation, and "use atrophy" from sustained periods of excessive workloads. ${ }^{2}$ In the era of lung-protective ventilation, even continuous ventilation (ie, "assist-control") modes often result in excessive patient work of breathing. This is largely explained by tidal volume mismatching despite adequate inspiratory flows. ${ }^{3-6}$ Moreover, excessive negative inspiratory muscle pressure $\left(\mathrm{P}_{\mathrm{mus}}\right)$ transmitted to the pleural space is associated with excessive trans-alveolar stresses that likely potentiate ventilator- 


\section{Expiratory Pause Maneuver to Assess Inspiratory Muscle Pressure}

induced lung injury as well as enhance pulmonary edema formation and worsen hypoxemia. ${ }^{4,70}$

A significant clinical problem in these circumstances is the lack of a noninvasive surrogate measure of $\mathrm{P}_{\text {mus }}$ that could help titrate both mechanical ventilation and sedation to minimize the risks of both disuse and use atrophy, and

\section{See the Related Editorial on Page 1779}

reduce the potential risk for self-induced lung injury from the generation of excessive negative transpulmonary pressures. ${ }^{10}$ Patient effort during assisted mechanical ventilation is measured by tidal changes in esophageal pressure as a signifier of $\Delta \mathrm{P}_{\text {mus }}$ that is used to calculate patient work of breathing. Accurate changes in esophageal pressure measurements require proper balloon positioning, signified by synchronous and close agreement between changes in esophageal pressure and occlusive airway pressure change $\left(\Delta \mathrm{P}_{\mathrm{aw}}\right)$ during a Baydur maneuver (ie, the standard inspiratory occlusion test). ${ }^{11}$ Because occluded $\Delta \mathrm{P}_{\mathrm{aw}}$ implicitly is the accepted standard for estimating $\Delta \mathrm{P}_{\text {mus }}$, we reasoned that, by introducing a brief expiratory pause hold (ie, threshold load) before patient-triggered inspiration, the resulting airway occlusion pressure could reasonably be used as a signifier for the "intended" effort that emanates from the respiratory centers. Therefore, such an expiratory pause maneuver might be a practical, expedient method to noninvasively assess inspiratory effort at the bedside.

This bench study investigated whether manually generated expiratory pause maneuver estimates of inspiratory effort are reasonably accurate and reproducible to be incorporated into clinical practice. We assessed 2 aspects of expiratory pause maneuver measurements: (1) its accuracy and reproducibility across multiple operators, intensity of simulated effort, ventilator modes, intensity of mechanical

Mr Kallet, Mr Phillips, Mr Summers, Mr Burns, Mr Pangilinan, Mr Carothers, and Mr Mangalinda are affiliated with the Respiratory Care Division. Dr Lipnick is affiliated with the Critical Care Division, Department of Anesthesia and Perioperative Care, University of California, San Francisco at Zuckerberg San Francisco General Hospital and Trauma Center, San Francisco, California.

Supplementary material related to this paper is available at http://www. rcjournal.com

Mr Kallet discloses relationships with Nihon Kohden and ContinuED. The other authors have disclosed no conflicts of interest.

Mr Pangilinan and Mr Summers presented a version of this study at AARC Congress 2018, held December 4-7, 2018, in Las Vegas, Nevada.

Correspondence: Richard H Kallet MSc RRT FAARC, 2070 Fell St. no. 1, San Francisco, CA. 94117-1878. E-mail: richkallet@gmail.com.

DOI: $10.4187 /$ respcare. 09047

\section{QUICK LOOK}

\section{Current knowledge}

Results of preliminary clinical studies suggest that airway pressure deflections during a brief airway occlusion reflect transpulmonary pressure and inspiratory muscle pressure during assisted mechanical ventilation. This maneuver might be useful in detecting inspiratory efforts that may increase the risk for both ventilatorinduced lung injury as well as acute inspiratory muscle injury.

\section{What this paper contributes to our knowledge}

This bench study demonstrated that standardization of such an expiratory pause maneuver generally produced consistent, reproducible measurements of airway occlusion pressure both within and between clinician operators as well as across ventilator modes and ventilator brands. Occlusion pressure tends to underestimate simulated muscle pressure by $\sim 1-2 \mathrm{~cm} \mathrm{H}_{2} \mathrm{O}$, with minor increases to $3 \mathrm{~cm} \mathrm{H}_{2} \mathrm{O}$ when simulated effort is highest.

support; and (2) whether its accuracy might be affected by PEEP and trigger sensitivity settings, and differences among how ventilators execute expiratory pause holds. To simplify the narrative simulated effort (ie, inspiratory $\mathrm{P}_{\text {mus }}$ change) is referred to as $\Delta \mathrm{P}_{\text {mus }}$ and occlusive airway pressure change is referred to as $\Delta \mathrm{P}_{\mathrm{aw}}$.

\section{Methods}

\section{Measurement Rationale}

The intention of the expiratory pause maneuver is to capture the initial pressure drop during an airway occlusion as an extension of the "pre-trigger phase" (ie, before pressurization of the ventilator circuit). ${ }^{12}$ The expiratory pause maneuver is based on the same assumptions that underlie the 100 -ms airway occlusion pressure test $\left(\mathrm{P}_{100}\right.$ or $\left.\mathrm{P}_{0.1}\right)$ used to signify central respiratory drive, that being to capture the "intended" respiratory motor-neuronal output. ${ }^{13}$ The distinction is that the expiratory pause maneuver is intended to capture peak inspiratory effort rather than respiratory drive per se (Fig. 1). Based on available (albeit limited) physiologic evidence, we reasoned that peak $\Delta \mathrm{P}_{\text {mus }}$ occurs early in the inspiratory phase, particularly at high levels of respiratory drive. When assuming a sufficient lag time (ie, trigger delay and/or circuit re-pressurization), quickly releasing the pause hold once a deflection in end-expiratory $\mathrm{P}_{\mathrm{aw}}$ is detected might capture the peak $\Delta \mathrm{P}_{\text {mus. }}$. It also might limit a potential bias from altered respiratory drive, which results from either 


\section{Expiratory Pause Maneuver to Assess Inspiratory Muscle Pressure}

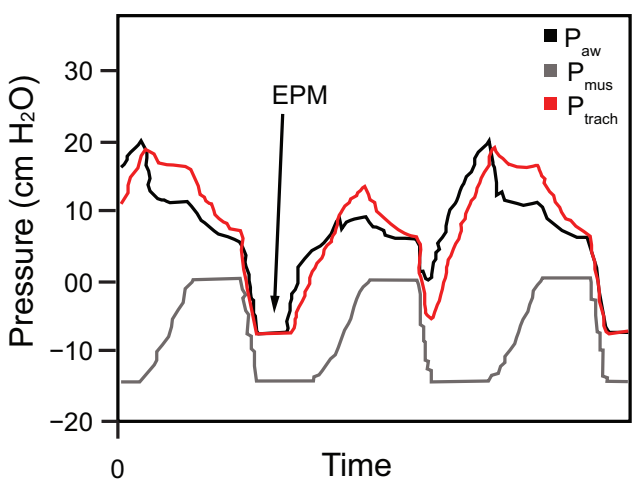

Fig. 1. Scalar pressure waveforms of an expiratory pause maneuver (EPM), followed by unobstructed simulated efforts (simulated muscle pressure is depicted in grey and airway pressure in black).

proprioceptive feedback or conscious perception of threshold loading.

\section{Ventilators and Settings}

Three ventilators capable of imposing an expiratory pause (negative inspiratory force or negative inspiratory force maneuver) were studied: Evita XL (Dräger, Telford, Pennsylvania), PB-980 (Medtronic, Minneapolis, Minnesota), and Avea (CareFusion, Yorba Linda, California). Each ventilator first underwent a full device check. Expiratory pause maneuver accuracy was tested in 4 modes: CPAP, pressure-support ventilation (PSV), volume control ventilation, and pressure-regulated volume control. CPAP was tested at $5 \mathrm{~cm} \mathrm{H}_{2} \mathrm{O}$ and PSV was tested at driving pressures of 10 and $15 \mathrm{~cm} \mathrm{H}_{2} \mathrm{O}$ above a PEEP of $5 \mathrm{~cm} \mathrm{H}_{2} \mathrm{O}$. For both volume control ventilation and pressure-regulated volume control, the settings were as follows: $f$ of 20 breaths/min, tidal volume of $500 \mathrm{~mL}$, inspiratory time of $0.85 \mathrm{~s}$, and a PEEP of $5 \mathrm{~cm} \mathrm{H}_{2} \mathrm{O}$. For PSV, a maximum (quickest) pressurization rate was used except for the protocol that examined post-trigger pressurization characteristics. For all protocols (except one that examined the influence of a trigger mechanism and sensitivity level), flow trigger was used and set to a sensitivity of $2 \mathrm{~L} / \mathrm{min}$.

\section{Model}

Spontaneous breathing was simulated by using an ASL5000 breathing simulator (IngMar Medical, Pittsburgh, Pennsylvania) set to a f of 25 breaths/min and inspiratory time of $0.85 \mathrm{~s}$, and time fraction (inspiratory time to the total breathing cycle time) of 0.35 . These values fell within the interquartile range of unassisted breathing reported in subjects with ARDS. ${ }^{14}$ The inspiratory phase was characterized by a $\mathrm{P}_{\text {mus }}$ rise time of $220 \mathrm{~ms}$, which was consistent with data derived from physiologic studies. ${ }^{15,16} \mathrm{P}_{\text {mus }}$ sustain and decay times were set at $0.410 \mathrm{~ms}$ and $220 \mathrm{~ms}$, respectively, to achieve the targeted inspiratory time. Mild, moderate, and high $\Delta \mathrm{P}_{\mathrm{mus}}$, of $-5,-10$, and $-15 \mathrm{~cm} \mathrm{H}_{2} \mathrm{O}$, respectively, were used. Simulated chest mechanics consisted of a compliance of $40 \mathrm{~mL} / \mathrm{cm} \mathrm{H}_{2} \mathrm{O}$ and a resistance of $5 \mathrm{~cm} \mathrm{H}_{2} \mathrm{O} / \mathrm{L} / \mathrm{s}$, producing inspiratory and expiratory time constants of $0.2 \mathrm{~s}$ (ie, 95\% monoexponential equilibration time of $800 \mathrm{~ms}$ ). An arbitrary pre hoc concordance between $\Delta \mathrm{P}_{\text {mus }}$ and $\Delta \mathrm{P}_{\mathrm{aw}}$ of $\mathrm{S}$ $2 \mathrm{~cm} \mathrm{H}_{2} \mathrm{O}$ was considered clinically reasonable.

\section{Expiratory Pause Maneuver Technique}

Before any experimental run, each author/investigator (hereafter referred to as "operator") had a practice session of $1-2$ min to rehearse his technique. For the Dräger Evita $\mathrm{XL}$ ventilator, the negative inspiratory force menu was accessed and the pressure scaler waveform was formatted to facilitate clear visualization of pressure deflections. The negative inspiratory force pause hold was activated after the peak expiratory flow and was released after a negative deflection was noted on subsequent inspiratory effort. The negative inspiratory force function also was used in the PB980 ventilator. Because scalar waveforms were not available during the negative inspiratory force maneuver on the PB980 ventilator, the operators had to respond to the sudden appearance of a negative deflection of the $\mathrm{P}_{\mathrm{aw}}$ waveform. For the Avea ventilator, the expiratory pause function was engaged while monitoring the scalar flow and pressure tracings (again formatted to facilitate clear visualization). The negative inspiratory force reported on each ventilator was recorded.

Because the expiratory pause maneuver duration must balance the likelihood of capturing peak effort while also preventing alterations in respiratory drive, we developed a uniform method for timing the expiratory pause maneuver and tested 3 release techniques: having the operators rapidly count " $1,2,3$ " before releasing the pause hold; " 1,2 " release; and " 1 " release. The goal was to achieve an expiratory pause maneuver duration of $\sim 500 \mathrm{~ms}$. The "1" release produced the briefest pause duration and was used for all expiratory pause maneuver measurements reported in this study (Supplementary Fig. 1 [see the supplementary materials at http://www.rcjournal.com])

\section{Intra- and Inter-Operator Variability and Expiratory Pause Maneuver Variability Between Ventilator Modes}

Between 4 and 7 operators performed 12 measurements each at every $\mathrm{P}_{\mathrm{mus}}$ level tested on each ventilator mode and/or settings tested. Expiratory pause maneuver data were analyzed within and between operators. Operator data also were combined to evaluate the overall impact of $\Delta$ $\mathrm{P}_{\text {mus }}$ intensity on $\Delta \mathrm{P}_{\mathrm{aw}}$ accuracy. Data from all the 
Table 1. Grouped Operator Comparisons of Expiratory Pause Maneuver Across Three Ventilators and Two Modes That Compare $\Delta \mathrm{P}_{\mathrm{aw}}$ With $\Delta \mathrm{P}_{\mathrm{mus}}$

\begin{tabular}{|c|c|c|c|c|}
\hline$\Delta \mathrm{P}_{\text {mus }}$ & $\mathrm{CPAP}, 5 \mathrm{~cm} \mathrm{H} \mathrm{H}_{2} \mathrm{O}$ & PS, $\Delta 10 / 5 \mathrm{~cm} \mathrm{H}_{2} \mathrm{O}$ & $\mathrm{PS}, \Delta 15 / 5 \mathrm{~cm} \mathrm{H}_{2} \mathrm{O}$ & $P$, ANOVA \\
\hline \multicolumn{5}{|c|}{ Dräger XL ventilator } \\
\hline $5 \mathrm{~cm} \mathrm{H}_{2} \mathrm{O}$ & $4 \pm 0$ & $3.9 \pm 0.5$ & $4.0 \pm 0.1$ & .17 \\
\hline $10 \mathrm{~cm} \mathrm{H}_{2} \mathrm{O}$ & $8.5 \pm 0.5$ & $8.0 \pm 0.1^{*}$ & $8.1 \pm 0.6^{*}$ & $<.001$ \\
\hline $15 \mathrm{~cm} \mathrm{H}_{2} \mathrm{O}$ & $12.6 \pm 1.0$ & $12.8 \pm 0.6$ & $12.5 \pm 0.7$ & .25 \\
\hline \multicolumn{5}{|c|}{ PB-980 ventilator } \\
\hline $5 \mathrm{~cm} \mathrm{H}_{2} \mathrm{O}$ & $4 \pm 0$ & $4 \pm 0$ & $4.0 \pm 0.1$ & .37 \\
\hline $10 \mathrm{~cm} \mathrm{H}_{2} \mathrm{O}$ & $8.6 \pm 0.5$ & $8 \pm 0^{\dagger}$ & $8 \pm 0^{\dagger}$ & $<.001$ \\
\hline $15 \mathrm{~cm} \mathrm{H}_{2} \mathrm{O}$ & $13 \pm 0^{\ddagger}$ & $12.9 \pm 0.3^{\ddagger}$ & $12.3 \pm 0.5$ & $<.001$ \\
\hline \multicolumn{5}{|l|}{ Avea ventilator } \\
\hline $5 \mathrm{~cm} \mathrm{H}_{2} \mathrm{O}$ & $3.9 \pm 0.3$ & $4 \pm 0^{\S}$ & $3.9 \pm 0.3$ & .01 \\
\hline $10 \mathrm{~cm} \mathrm{H}_{2} \mathrm{O}$ & $8.8 \pm 0.4$ & $8.8 \pm 0.4$ & $8.7 \pm 0.6$ & .43 \\
\hline $15 \mathrm{~cm} \mathrm{H}_{2} \mathrm{O}$ & $13.8 \pm 0.4$ & $13.5 \pm 0.9^{\prime \prime}$ & $13.5 \pm 0.9$ & $<.001$ \\
\hline \multicolumn{5}{|c|}{$\begin{array}{l}\text { Data are presented as mean } \pm \mathrm{SD} \\
*_{P}<.001 \text { vs CPAP } 5 . \\
\dagger P<.001 \text { vs CPAP. } \\
\vdots P<.001 \text { vs PS } \Delta 15 / 5 . \\
\S P=.003 \text { vs CPAP } 5 \text { and } \mathrm{PS} \Delta 15 / 5 . \\
\| P=.002 \text { vs CPAP } 5 \text { and } \mathrm{PS} \Delta 15 / 5 . \\
\Delta \mathrm{P}_{\text {aw }}=\text { occlusive airway pressure change } \\
\Delta \mathrm{P}_{\text {mus }}=\text { simulated inspiratory muscle pres } \\
\mathrm{PS}=\text { pressure support } \\
\mathrm{ANOVA}=\text { analysis of variance }\end{array}$} \\
\hline
\end{tabular}

modalities were grouped together to calculate the correlation coefficient, bias, and precision of $\Delta \mathrm{P}_{\mathrm{aw}}$ measurements on each ventilator compared with $\Delta \mathrm{P}_{\text {mus }}$ on the IngMar ASL5000 breathing simulator.

\section{Supplementary Protocols}

For completeness, we studied whether ventilator settings such as different trigger mechanisms, sensitivity threshold, PEEP, post-trigger pressurization intensity, and circuit repressurization time might influence expiratory pause maneuver measurements. The methodology and results can be found in the supplementary materials (see the supplementary materials at http://www.rcjournal.com).

\section{Statistical Analysis}

Statistical analysis was done by using Prism software 8.3.0 (GraphPad, San Diego, California). Multiple comparisons were assessed by using analysis of variance and Tukey-Kramer posttests, and discreet comparisons were made by using paired $t$ tests. Variability of both intraindividual and inter-individual measurements were assessed by the percentage of $\Delta \mathrm{P}_{\mathrm{aw}}$ measurements deviating $>2 \mathrm{~cm} \mathrm{H}_{2} \mathrm{O}$ from $\Delta \mathrm{P}_{\text {mus. This was done with }}$ groupings of $\Delta \mathrm{P}_{\text {mus }}$ and by mode. Correlation was assessed by using the Pearson $r$ test, bias and precision were assessed by the Bland-Altman method, and categorical variables were compared by using the Fisher exact test. Alpha was set at .05.

\section{Results}

\section{Measurement Accuracy and Variability with Increasing Simulated Effort}

Grouped $\Delta \mathrm{P}_{\mathrm{aw}}$ measurements across effort intensity, level, and mode of ventilatory support demonstrated reasonable concordance with $\Delta \mathrm{P}_{\text {mus }}$, regardless of the ventilator used (Tables 1 and 2). However, $\Delta \mathrm{P}_{\mathrm{aw}}$ accuracy deteriorated when $\Delta \mathrm{P}_{\text {mus }}$ reached $15 \mathrm{~cm} \mathrm{H}_{2} \mathrm{O}$, and most often occurred when PSV was $15 \mathrm{~cm} \mathrm{H}_{2} \mathrm{O}$. Of the 129 instances in $90 \%$, the error exceeded pre hoc accuracy criteria by only $1 \mathrm{~cm} \mathrm{H}_{2} \mathrm{O}$ (ie, 3 vs $\leq 2 \mathrm{~cm} \mathrm{H}_{2} \mathrm{O}$ ) (Table 3 ). The mean $\Delta \mathrm{P}_{\mathrm{aw}}$ underestimated $\Delta \mathrm{P}_{\text {mus }}$ by $\sim 1,2$, and $2.5 \mathrm{~cm} \mathrm{H}_{2} \mathrm{O}$ at simulated efforts of 5, 10, and $15 \mathrm{~cm} \mathrm{H}_{2} \mathrm{O}$, respectively. By contrast, the mean $\Delta \mathrm{P}_{\mathrm{aw}}$ measured by the Avea ventilator underestimated $\Delta$ $\mathrm{P}_{\text {mus }}$ by $\leq 1.5 \mathrm{~cm} \mathrm{H}_{2} \mathrm{O}$ under all test conditions. During volume control ventilation and pressure-regulated volume control, $\Delta \mathrm{P}_{\mathrm{aw}}$ underestimated $\Delta \mathrm{P}_{\text {mus }}$ by $0.5-1.1 \mathrm{~cm} \mathrm{H}_{2} \mathrm{O}$ when effort was 5 and $10 \mathrm{~cm} \mathrm{H}_{2} \mathrm{O}$ and by $1.1-1.8 \mathrm{~cm} \mathrm{H}_{2} \mathrm{O}$ when $\Delta \mathrm{P}_{\text {mus }}$ was $15 \mathrm{~cm} \mathrm{H}_{2} \mathrm{O}$.

\section{Inter-Operator Variability and Increased Simulated Effort}

Small, statistically significant differences in $\Delta \mathrm{P}_{\text {aw }}$ were found among the individual operators across both the intensity of effort and the level of ventilatory support, with notable divergence only when $\Delta \mathrm{P}_{\text {mus }}$ reached $15 \mathrm{~cm} \mathrm{H}_{2} \mathrm{O}$ 


\section{Expiratory Pause Maneuver to Assess Inspiratory Muscle Pressure}

(Supplementary Tables 1-3 [see the supplementary materials at http://www.rcjournal.com]).

Table 2. Grouped Operator Comparisons Between $\Delta \mathrm{P}_{\mathrm{aw}}$ at Each Level of $\Delta \mathrm{P}_{\text {mus }}$ Across Three Ventilators and Two Continuous Ventilation Modes

\begin{tabular}{|c|c|c|c|}
\hline Mode & $\begin{array}{c}\Delta \mathrm{P}_{\text {mus }}, 5 \mathrm{~cm} \\
\mathrm{H}_{2} \mathrm{O}\end{array}$ & $\begin{array}{c}\Delta \mathrm{P}_{\text {mus }}, 10 \mathrm{~cm} \\
\mathrm{H}_{2} \mathrm{O}\end{array}$ & $\begin{array}{c}\Delta \mathrm{P}_{\text {mus }}, 15 \mathrm{~cm} \\
\mathrm{H}_{2} \mathrm{O}\end{array}$ \\
\hline \multicolumn{4}{|c|}{ Dräger XL ventilator } \\
\hline VCV & $3.9 \pm 0.5$ & $9.0 \pm 0.1$ & $13.8 \pm 0.4$ \\
\hline PRVC & $4.0 \pm 0.1$ & $9.0 \pm 0.0$ & $13.5 \pm 0.5$ \\
\hline \multicolumn{4}{|c|}{ PB-980 ventilator } \\
\hline VCV & $4.6 \pm 0.5$ & $9.0 \pm 0.2$ & $13.2 \pm 0.6$ \\
\hline PRVC & $4.8 \pm 0.4^{*}$ & $9.5 \pm 0.5^{\dagger}$ & $13.9 \pm 0.3^{\dagger}$ \\
\hline \multicolumn{4}{|l|}{ Avea ventilator } \\
\hline VCV & $4.1 \pm 0.4$ & $8.9 \pm 0.2$ & $13.8 \pm 0.2$ \\
\hline PRVC & $4.1 \pm 0.3 *$ & $9.0 \pm 0.1^{\dagger}$ & $13.9 \pm 0.2^{\dagger}$ \\
\hline \multicolumn{4}{|c|}{$\begin{array}{l}\text { Data are presented as mean } \pm \mathrm{SD} \\
{ }^{*} P=.03 \text { vs } \mathrm{VCV} \text {. } \\
\dagger P<.001 \text { vs } \mathrm{VCV} \text {. } \\
\Delta \mathrm{P}_{\text {aw }}=\text { occlusive airway pressure change } \\
\Delta \mathrm{P}_{\mathrm{m}}=\text { simulated inspiratory muscle pressure change } \\
\mathrm{VCV}=\text { volume control ventilation } \\
\mathrm{PRVC}=\text { pressure-regulated volume control }\end{array}$} \\
\hline
\end{tabular}

\section{Differences Among Ventilators}

Grouped operator data revealed no clinically appreciable difference among the ventilators in concordance between $\Delta$ $\mathrm{P}_{\mathrm{aw}}$ and $\Delta \mathrm{P}_{\text {mus }}$ (Fig. 2). The correlation between $\Delta \mathrm{P}_{\mathrm{aw}}$ and $\Delta \mathrm{P}_{\text {mus }}$ was the same for each ventilator $(\mathrm{r}=0.99)$. The mean bias (standard deviation) and precision (95\% limit of agreement) were similar but improved marginally from the Dräger XL to the PB-980 and Avea ventilators: $-1.86 \pm$ 0.80 ( -3.44 to -0.29$),-1.35 \pm 0.77$ ( -2.86 to 0.15$)$, and $1.25 \pm 0.56(-2.36$ to -0.15$)$, respectively (Supplementary Figs. 2 - 4 [see the supplementary materials at http://www. rcjournal.com]). The number of incidences of when $\Delta \mathrm{P}_{\mathrm{aw}}$ exceeded the pre hoc accuracy threshold of $>2 \mathrm{~cm} \mathrm{H}_{2} \mathrm{O}$ was 129 , with the distribution across ventilators of 40,39 , and $21 \%$ for the Dräger XL, PB-980, and Avea ventilators, respectively. Only the incidences between the Dräger XL and Avea ventilators were significant: odds ratio 1.80 95\% CI $(1.12-2.93) ; P=.02$.

\section{Discussion}

Our primary finding was that a manually generated expiratory pause maneuver under simulated breathing

Table 3. The incidence of $\Delta \mathrm{P}_{\mathrm{aw}}$ Underestimating Simulated $\Delta \mathrm{P}_{\text {mus }}$ by $>2 \mathrm{~cm} \mathrm{H}_{2} \mathrm{O}$ Across Both Intensity of Inspiratory Effort and Ventilatory Support

\begin{tabular}{|c|c|c|c|c|}
\hline $\begin{array}{l}\text { Mode } \\
\text { Dräger XL ventilator }\end{array}$ & $\Delta \mathrm{P}_{\text {mus }}, 5 \mathrm{~cm} \mathrm{H} \mathrm{H}_{2} \mathrm{O}$ & $\Delta \mathrm{P}_{\mathrm{mus}}, 10 \mathrm{~cm} \mathrm{H}_{2} \mathrm{O}$ & $\Delta \mathrm{P}_{\mathrm{mus}}, 15 \mathrm{~cm} \mathrm{H}_{2} \mathrm{O}$ & High Aberrancy ${ }^{* \dagger}$ \\
\hline CPAP & $0 / 48$ & $1 / 48(2)$ & $10 / 48(21)$ & $3 / 144(2)$ \\
\hline PS-10 & $1 / 48(2.1)$ & $1 / 48(2)$ & $8 / 48(17)$ & $2 / 144(1)$ \\
\hline PS-15 & $0 / 48$ & $2 / 48(4)$ & $17 / 48(35)$ & $4 / 144(3)$ \\
\hline VCV & $2 / 60(3)$ & $0 / 60$ & $0 / 60$ & $2 / 180(1)$ \\
\hline PRVC & $0 / 60$ & $0 / 60$ & $0 / 60$ & NA \\
\hline \multicolumn{5}{|l|}{ PB-980 ventilator } \\
\hline CPAP & $0 / 60$ & $0 / 60$ & $0 / 60$ & NA \\
\hline PS-10 & $0 / 60$ & $0 / 60$ & $7 / 60(11.7)$ & $0 / 180$ \\
\hline PS-15 & $0 / 60$ & $0 / 60$ & $40 / 60(66.6)$ & $0 / 180$ \\
\hline VCV & $0 / 60$ & $0 / 60$ & $1 / 60(1.6)$ & $1 / 180(<1)$ \\
\hline PRVC & $0 / 60$ & $0 / 60$ & $0 / 60$ & NA \\
\hline \multicolumn{5}{|l|}{ Avea ventilator } \\
\hline CPAP & $0 / 48$ & $0 / 48$ & $0 / 48$ & NA \\
\hline PS-10 & $0 / 48$ & $0 / 48$ & $12 / 48(25)$ & $0 / 144$ \\
\hline PS-15 & $0 / 48$ & $3 / 48(6)$ & $12 / 48(25)$ & $0 / 144$ \\
\hline $\mathrm{VCV}$ & $0 / 48$ & $0 / 48$ & $0 / 48$ & $0 / 144$ \\
\hline PRVC & $0 / 48$ & $0 / 48$ & $0 / 48$ & $0 / 144$ \\
\hline $\begin{array}{l}\text { Data are presented as no./total } \\
\text { *Most errors were only } 1 \mathrm{~cm} \\
\dagger{ }^{\dagger} \text { High aberrancy was added to } \\
\Delta \mathrm{P}_{\text {aw }}=\text { occlusive airway pres } \\
\Delta \mathrm{P}_{\text {mus }}=\text { simulated inspiratory } \\
\mathrm{PS}=\text { pressure support } \\
\mathrm{VCV}=\text { volume control ventila } \\
\mathrm{PRVC}=\text { pressure-regulated vo } \\
\mathrm{NA}=\text { not applicable (no data) }\end{array}$ & $\begin{array}{l}\text { nts }(\%) . \\
\text { cidence of measurements d } \\
\text { re change }\end{array}$ & $\begin{array}{l}\text { ion (ie, } 3 \mathrm{~cm} \mathrm{H}_{2} \mathrm{O} \text { ). } \\
\text { ively underestimating } \Delta \mathrm{P}_{\mathrm{mu}}\end{array}$ & & \\
\hline
\end{tabular}




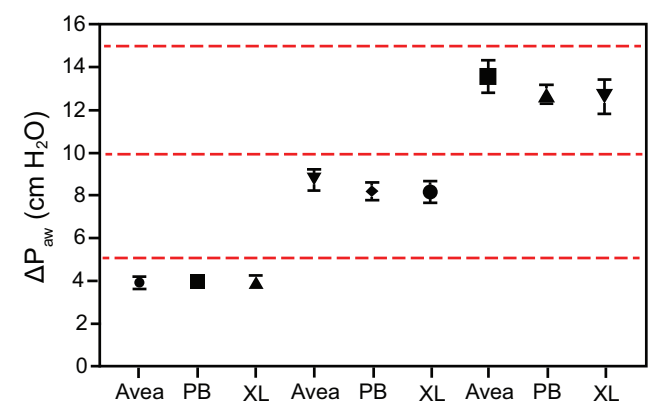

Fig. 2. Change in occlusion airway pressure $\left(\Delta P_{a w}\right)$ during an expiratory pause maneuver across 3 ventilators, which represent 3 levels of simulated muscle pressure $\left(\Delta \mathrm{P}_{\text {mus }}\right)$ depicted as red hash lines. $\mathrm{PB}=$ Puritan-Bennett 980 ventilator; $\mathrm{XL}=$ Dräger $\mathrm{XL}$ ventilator.

conditions yielded a $\Delta \mathrm{P}_{\mathrm{aw}}$ that was reasonably accurate in reflecting $\Delta \mathrm{P}_{\text {mus }}$ and reproducible across multiple operators and ventilator modes. Thus, we believe that the technique can reasonably be considered for further evaluation during routine clinical practice. Of 2,412 discreet measurements made across the modes and ventilator brands, $\Delta \mathrm{P}_{\mathrm{aw}}$ underestimated $\Delta \mathrm{P}_{\mathrm{mus}}$ by $\leq 2 \mathrm{~cm} \mathrm{H}_{2} \mathrm{O}$ in $\sim 95 \%$ of instances, with only $4.9 \%$ that deviated by 3 $\mathrm{cm} \mathrm{H}_{2} \mathrm{O}$ and $0.5 \%$ that deviated by $\geq 4 \mathrm{~cm} \mathrm{H}_{2} \mathrm{O}$. Expiratory pause maneuver accuracy was reasonably consistent both within and between the operators. Deterioration in accuracy occurred mostly when both simulated effort and PSV level reached $15 \mathrm{~cm} \mathrm{H}_{2} \mathrm{O}$, and, as examined in the supplementary protocols (see the supplementary materials at http://www.rcjournal.com), expiratory pause maneuver accuracy was unaffected by the trigger mechanism, sensitivity level, speed of circuit repressurization, or PEEP level.

Since we began our study in mid 2018, other investigators have validated the expiratory pause maneuver clinically compared with invasive techniques by using esophageal manometry. ${ }^{17-20}$ Bertoni et $\mathrm{al}^{17}$ randomly applied the expiratory pause maneuver by using a 1-2 s pause while simultaneously measuring the changes in esophageal pressure and diaphragmatic electromyography. They found predicted values of $\mathrm{P}_{\text {mus }}$ and transalveolar pressure (based on estimated chest wall elastance when using the expiratory pause maneuver-generated $\Delta \mathrm{P}_{\mathrm{aw}}$ ) accurately detected excessive levels of measured $\mathrm{P}_{\mathrm{mus}}$ and transalveolar pressure.

Moreover, excessive levels of $\mathrm{P}_{\mathrm{mus}}$ and transalveolar pressure were found during most observations; this supports the rationale for the expiratory pause maneuver in clinical practice. Roesthuis et $\mathrm{al}^{20}$ also found that the expiratory pause maneuver-generated $\Delta \mathrm{P}_{\mathrm{aw}}$ accurately detected excessive levels of measured $\mathrm{P}_{\mathrm{mus}}$ and trans-alveolar pressure (ie, $>15$ and $>20 \mathrm{~cm} \mathrm{H}_{2} \mathrm{O}$, respectively). In addition, expiratory pause maneuver generated $\Delta \mathrm{P}_{\mathrm{aw}}$ was strongly correlated with both respiratory $\mathrm{P}_{\text {mus }}$-time

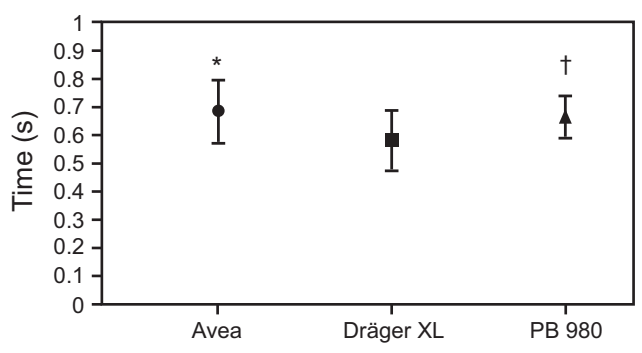

Fig. 3. Expiratory pause maneuver duration of all the operators across ventilators. $P<.001$ by analysis of variance (ANOVA) and ${ }^{*} P=.003$ vs Dräger $\mathrm{XL}$ ventilator, $\uparrow P=.002$ vs Dräger $\mathrm{XL}$ ventilator.

product (a signifier of respiratory muscle oxygen consumption) and power output. Another study found that the combination of elevated expiratory pause maneuvergenerated $\Delta \mathrm{P}_{\mathrm{aw}}$ and $\mathrm{P}_{0.1}$ was associated with relapse respiratory failure in subjects for whom weaning attempts failed. ${ }^{19}$

In clinical practice, numerous personnel are involved so that the validity of expiratory pause maneuver-generated $\Delta \mathrm{P}_{\mathrm{aw}}$ likely depends on the ability to recognize effort onset and to quickly release the expiratory pause before either unconscious or conscious recognition of threshold loading. The detection and response to threshold loading may enhance the inspiratory effort, which gives the false impression of excessive effort when none exists. In our limited clinical experience, we occasionally encountered this phenomenon in patients who were lightly sedated or fully conscious and, in these limited instances, it appeared as a secondary negative spike in $\mathrm{P}_{\mathrm{aw}}$ (Supplementary Fig. 5 [see the supplementary materials at http://www.rcjournal.com]). Detection latency associated with threshold loading is discussed in more detail in the supplementary materials (see the supplementary materials at http://www.rcjournal.com).

It is because of these concerns that we attempted to minimize the expiratory pause maneuver duration toward a rarely achieved goal of $500 \mathrm{~ms}$. We suspect that excessive measurement discrepancies were caused by a too brief expiratory pause maneuver. Although we lack sufficient data to support this, it is notable that the fewest discrepancies occurred with the Avea ventilator, which also had a slightly higher expiratory pause maneuver duration compared with the other ventilators (Fig. 3). The overall low incidence of measurement discrepancies may be considered a reasonable trade-off during clinical practice.

Therefore, it is encouraging that expiratory pause maneuver durations of 1-2 s did not seem to alter inspiratory effort during clinical studies, ${ }^{17}$ with some investigators suggesting that the expiratory pause maneuver duration can be increased to $5 \mathrm{s.}{ }^{22}$ However, information with regard to sedation assessment scores was not 


\section{Expiratory Pause Maneuver to Assess Inspiratory Muscle Pressure}

reported. Hence, their findings do not exclude the possibility that some patients may perceive sudden threshold loading that results in inaccurate assessment of patient effort or estimated lung stress. This would be more likely to occur in patients with high respiratory drive and/or light sedation. Therefore, we think it prudent to limit the expiratory pause maneuver duration to $\leq 1 \mathrm{~s}$ until further information on the impact of sedation and drive on expiratory pause maneuver-generated $\Delta \mathrm{P}_{\mathrm{aw}}$ becomes available.

The major limitation is that this was a bench study in which we imputed a spontaneous breathing pattern that might reasonably approximate patients with ARDS. To our knowledge, the characteristics of inspiratory flow and $\mathrm{P}_{\text {mus }}$ development have never been comprehensively explored since the initial studies conducted $\sim 70$ years ago. ${ }^{15,16,23}$ Therefore, repeating this experiment by imputing different temporal values for inspiratory pressure rise, sustain, and decay might produce different results in terms of intra- and inter-operator accuracy and/or variability. It is also important to emphasize that the intention of expiratory pause maneuver-generated $\Delta$ $\mathrm{P}_{\mathrm{aw}}$ is to produce only a clinically useful approximation for either $\mathrm{P}_{\mathrm{mus}}$ or trans-alveolar pressure during unobstructed breathing. A more accurate assessment would require invasive measurement of chest wall elastance with esophageal manometry and also in estimating the effects of chest wall motion. ${ }^{22}$

\section{Conclusions}

Under simulated breathing conditions, when both compliance and airways resistance are low, expiratory pause maneuver-generated $\Delta \mathrm{P}_{\text {aw }}$ approximates $\Delta \mathrm{P}_{\text {mus }}$ that varied little among multiple operators when using the same technique. Expiratory pause maneuver measurements are relatively stable across ventilation modes, settings, and the brand of ventilators tested. However, under the modeling conditions and technique tested accuracy tends to deteriorate when both inspiratory effort and PSV levels reach $15 \mathrm{~cm} \mathrm{H}_{2} \mathrm{O}$ by using an expiratory pause maneuver duration of $<1 \mathrm{~s}$. Nonetheless, the expiratory pause maneuver is an easy-to-perform, clinically practical, noninvasive technique that may be useful in monitoring inspiratory effort during assisted mechanical ventilation.

\section{REFERENCES}

1. Roussos C, Macklem PT. The respiratory muscles. N Engl J Med 1982;307(13):786-797.

2. Kallet RH. Patient-ventilator interaction during acute lung injury, and the role of spontaneous breathing: part 1: respiratory muscle function during critical illness. Respir Care 2011;56(2):181-189.
3. Kallet RH, Alonso JA, Diaz M, Campbell AR, Mackersie RC, Katz JA. The effects of tidal volume demand on work of breathing during simulated lung-protective ventilation. Respir Care 2002;47(8):898909.

4. Kallet RH, Alonso JA, Luce JM, Matthay MA. Exacerbation of acute pulmonary edema during assisted mechanical ventilation using a lowtidal volume, lung-protective ventilator strategy. Chest 1999;116 (6): 1826-1832.

5. Kallet RH, Campbell AR, Dicker RA, Katz JA, Mackersie RC. Effects of tidal volume on work of breathing during lung-protective ventilation in patients with acute lung injury and acute respiratory distress syndrome. Crit Care Med 2006;34(1):8-14.

6. Kallet RH, Campbell AR, Dicker RA, Katz JA, Mackersie RC. Work of breathing during lung-protective ventilation in patients with acute lung injury and acute respiratory distress syndrome: a comparison between volume and pressure-regulated breathing modes. Respir Care 2005;50(12):1623-1631.

7. Langer T, Vecchi V, Belenkiy SM, Cannon JW, Chung KK, Cancio $\mathrm{LC}$, et al. Extracorporeal gas exchange and spontaneous breathing for the treatment of acute respiratory distress syndrome: an alternative to mechanical ventilation?* Crit Care Med 2014;42(3):e211e220.

8. Yoshida T, Uchiyama A, Matsuura N, Mashimo T, Fujino Y. Spontaneous breathing during lung-protective ventilation in an experimental acute lung injury model: high transpulmonary pressure associated with strong spontaneous breathing effort may worsen lung injury. Crit Care Med 2012;40(5):1578-1585.

9. Kallet RH, Daniel BM, Gropper M, Matthay MA. Acute pulmonary edema following upper airway obstruction: case reports and brief review. Respir Care 1998;43(6):476-480.

10. Marini JJ, Gattinoni L. Management of COVID-19 respiratory distress. JAMA 2020;323(22):2329-2330.

11. Baydur A, Cha EJ, Sassoon CS. Validation of esophageal balloon technique at different lung volumes and postures. J Appl Physiol (1985) 1987;62(1):315-321.

12. Sassoon CS. Triggering of the ventilator in patient-ventilator interactions. Respir Care 2011;56(1):39-51.

13. Marini JJ. Monitoring during mechanical ventilation. Clin Chest Med 1988;9(1):73-100.

14. Kallet RH, Hemphill JC III, Dicker RA, Alonso JA, Campbell AR, Mackersie RC, et al. The spontaneous breathing pattern and work of breathing of patients with acute respiratory distress syndrome and acute lung injury. Respir Care 2007;52(8):989-995.

15. Proctor DF, Hardy JB. Studies of respiratory air flow; significance of the normal pneumotachogram. Bull Johns Hopkins Hosp 1949;85 (4):253-280.

16. Silverman L, Lee G, Plotkin T, Sawyers LA, Yancey AR. Air flow measurements on human subjects with and without respiratory resistance at several work rates. AMA Arch Ind Hyg Occup Med 1951;3 (5):461-478.

17. Bertoni M, Telias I, Urner M, Long M, Del Sorbo L, Fan E, et al. A novel non-invasive method to detect excessively high respiratory effort and dynamic transpulmonary driving pressure during mechanical ventilation. Crit Care 2019;23(1):346.

18. Bertoni M, Spadaro S, Goligher EC. Monitoring patient respiratory effort during mechanical ventilation: lung and diaphragm-protective ventilation. Crit Care 2020;24(1):106.

19. Esnault P, Cardinale M, Hraiech S, Goutorbe P, Baumstrack K, Prud'homme E, et al. High respiratory drive and excessive respiratory efforts predict relapse of respiratory failure in critically ill patients with COVID-19. Am J Respir Crit Care Med 2020;202 (8):1173-1178.

20. Roesthuis L, van den Berg M, van der Hoeven H. Non-invasive method to detect high respiratory effort and transpulmonary driving 


\section{Expiratory Pause Maneuver to Assess Inspiratory Muscle Pressure}

pressures in COVID-19 patients during mechanical ventilation. Ann Intensive Care 2021;11(1):26.

21. Doorduin J, Nollet JL, Vugts MPAJ, Roesthuis LH, Akankan F, van der Hoeven JG, et al. Assessment of dead-space ventilation in patients with acute respiratory distress syndrome: a prospective observational study. Crit Care 2016;20(1):121.
22. Dianti J, Bertoni M, Goligher EC. Monitoring patient-ventilator interaction by an end-expiratory occlusion maneuver. Intensive Care Med 2020;46(12):2338-2341.

23. Proctor DF, Hardy JB, McLean R. Studies of respiratory air flow. II. Observations on patients with pulmonary disease. Bull Johns Hopkins Hosp 1950;87(4):255-289.

This article is approved for Continuing Respiratory Care Education credit. For information and to obtain your CRCE

(free to AARC members) visit 